\title{
Preparation, Characterization, and Electrostatic Dissipating Properties of Poly(oxyalkylene)-Segmented Polyureas
}

\author{
Jiang-Jen LIN, ${ }^{\dagger}$ Jun-Zhe JAN, and Feng-Po TSENG \\ Department of Chemical Engineering, National Chung-Hsing University, Taichung 402, Taiwan
}

(Received September 25, 2000; Accepted January 4, 2001)

\begin{abstract}
A family of poly(oxyalkylene)-segmented and urea-linkaged polymers were prepared from the reaction of isophorone diisocyanate (IPDI) or toluene-2,4-diisocyanate (TDI) and poly(oxyalkylene)diamines at 1:1 or 1:2 molar ratio. Their structures were characterized by using IR and GPC. The chemical structures with respect to oxyalkylene backbone, terminal $-\mathrm{NH}_{2}$, uriedo linkage, weight fraction, and crystallinity of the involved poly(oxyethylene) segments were correlated to the measurement of surface resistivity. The oligomeric polyureas prepared from poly(oxyethylene)diamine generally had a lower surface resistivity than the starting amine due to the lowering crystallinity. The incorporation of poly(oxyethylene) segments proportionally increased hydrophilicity and consequently lowered surface resistivity as low as $10^{7.4} \Omega \mathrm{sq}^{-1}$ in comparison with $10^{9.8-10.0} \Omega \mathrm{sq}^{-1}$ for the semi-crystalline starting amines. Amine termination in oligomers also contributed to the lowering of surface resistivities. The comparisons between polyurethanes and polyureas further revealed the importance of hydrogen bonding involving mechanism for the electron transfers.

KEY WORDS Polyurea / Hydrophilicity / Crystallinity / Electrostatic Dissipating / Poly(oxyethylene) /
\end{abstract}

Generally, most polymeric materials have low electrical conductivity and a tendency of accumulating electrostatics. ${ }^{1}$ Recent advances in electronic industry ${ }^{2-5}$ promote new materials having electrostatic dissipating ability for applications in housing or packaging magnetic and electronic equipment. These antistatic materials have a common surface resistivity in the range of $10^{12}$ to $10^{6} \Omega \mathrm{sq}^{-1}$. These materials require a low resistivity for dissipating the accumulated electrostatic charges, however, the resistivity lower than $10^{6} \Omega \mathrm{sq}^{-1}$ may cause a sudden sparking or arcing. ${ }^{2}$

Regarding to the electric conducting mechanism, it is known that polyacetylene-type conducting polymers ${ }^{3,6}$ and ionic conducting materials ${ }^{7}$ can conduct electron transfer through conjugated $\pi$ bonds of the polymer backbone or metal ion hopping, respectively. On the other hand, the electrostatic dissipation of polymeric materials is considered to go through a charge transfer mechanism involving hydrogen bonding. ${ }^{2,8,9}$ The effective materials are often the amphiphilic polymers ${ }^{10}$ consisting of hydrophilic functionality such as poly(ethylene glycol). ${ }^{11}$ For example ${ }^{2}$ polyether-ester-amides and poly(oxyethylene)-modified poly- $\varepsilon$-caprolactam, prepared from the copolymerization involving a hydrophilic poly(ethylene glycol) monomer, were used as antistatic materials compatible with polyesters and polyamides.

Polyurethane and polyurea are classes of thermal plastic polymers with significant industrial importance. ${ }^{12}$ However, the electrostatic dissipating properties of polyurethane and polyurea had been rarely studied. Previously, we reported ${ }^{13}$ the preparation of urethane-containing polymeric electrostatic dissipating materials and also investigated the factors controlling electrostatic dissipation. By using the coupling reaction involving isophorone diisocyanate (IPDI), various molecular weights of poly(ethylene glycol)s (PEGs) and poly(propylene glycol)s (PPGs) were incorporated into oli- gomeric and polymeric urethanes. It was found that the PEG-segmented polyurethanes showed lower surface resistivities than the more crystalline PEG-1000, 2000, and 8000 starting materials. In another studies, poly (oxyethylene)-segmented polyamides ${ }^{14}$ and epoxies ${ }^{15}$ were prepared and the factors controlling surface resistivities were revealed. The weight fraction of the poly (oxyethylene)s in the structure plays an important role for lowering the surface resistivity. In this paper, we compare the different structures of the polymer backbones between the poly(oxyalkylene)-segmented polyurethanes and polyureas to reveal the importance of hydrogen bonding. Other factors such as segmental crystallinity, as well as the structural variation (such as $-\mathrm{NH}_{2}$ vs. $-\mathrm{OH}$ termini and oxypropylene vs. oxyethylene backbones) are also correlated to the electrostatic dissipation.

\section{EXPERIMENTAL}

\section{Materials}

Isophorone diisocyanate (IPDI) and 2,4-toluene diisocyanate (TDI) from Aldrich Chemical Co. or Merck were distilled to remove impurity. Poly(propylene glycol)s (PPG-400 and PPG-2000) and poly(ethylene glycol)s (PEG-2000 and PEG-8000) from Aldrich Chemical Co. or Merck were used without purification. Dibutyl tin dilaurate as a catalyst was supplied by Aldrich and diluted with toluene in 1:1 ratio by weight before use. A family of commercially available poly ( oxyethyleneoxypropylene)amines, trade name Jeffamine ${ }^{\circledR}$ Amines, were obtained from Huntsman Chemical Co. or Aldrich Chemical Co. and used without purification. They included poly(oxypropylene) bis(2-aminopropyl ether) of $400 M_{\mathrm{w}}$ and $\sim 2000 M_{\mathrm{w}}$ (Jeffamine ${ }^{\circledR} \mathrm{D}-400$ and D-2000, respectively), poly(oxyethylene-oxypropylene) bis(2aminopropyl ether) of $\sim 2000 M_{\mathrm{w}}$ and $\sim 6000 M_{\mathrm{w}}$ (Jeffamine ${ }^{\circledR}$ ED-2001 and ED-6000, respectively). These 
Poly(oxypropylene) bis(2-aminopropyl ether)

$$
\begin{gathered}
\mathrm{H}_{2} \mathrm{NCHCH}_{2}\left(\mathrm{OCH}_{2} \mathrm{CH}\right)_{x} \mathrm{NH}_{2} \\
\mathrm{x}=5-6 \text { (Approx. } \mathrm{Mw}=400 \text {; Jeffamine }{ }^{\circledR} \mathrm{D}-400 \text { ) } \\
\mathrm{x}=33 \text { (Approx. } \mathrm{Mw}=2000 ; \text { Jeffamine }{ }^{\circledR} \mathrm{D}-2000 \text { ) }
\end{gathered}
$$

Poly(ethylene glycol) bis(2-aminopropyl ether)<smiles>CCCOCCCOCCC(C)OCC(C)N</smiles>

Average $a+c=5.0, b=39.5\left(\right.$ Approx. $\mathrm{Mw}=2000 ;$ Jeffamine $\left.{ }^{\circledR} \mathrm{ED}-2001\right)$

Average $a+c=4.0, b=138$ (Approx. $\mathrm{Mw}=6000$; Jeffamine $\left.{ }^{\circledR} \mathrm{ED}-6000\right)$

Figure 1. Chemical structures of poly(oxyalkylene)amines.

commercially available compounds ${ }^{16,17}$ consist of poly(oxypropylene) block for D-series or poly(oxypropylene)$b$-poly(oxyethylene)- $b$-poly(oxypropylene) triblock for ED-series and the capped amino-propyl groups. These predominant oxyethylene-rich compounds are watersoluble and contain $39 / 5$ and $138 / 4$ unit ratios of oxyethylene/oxypropylene per mole for ED-2001 and ED-6000, respectively. The poly(oxypropylene) bis(2-aminopropyl ether) with $M_{\mathrm{w}}$ of 2000 (D-2000) and 400 (D-400) are water-insoluble. The chemical structures of the Jeffamine ${ }^{\mathbb{R}}$ Amines are shown in Figure 1 .

Preparation of Urea Oligomers and Polyureas Containing Poly(oxyalkylene)-Segments

The typical experimental procedures for the reactions of poly(oxyalkylene)-diamines and diisocyanates to prepare the poly(oxyalkylene)-segmented urea oligomers and polyureas are described in the followings.

\section{ED-2001 / IPDI Adduct at 2: 1 Molar Ratio}

To a $250 \mathrm{~mL}$ of three-necked round-bottomed flask, equipped with a mechanical stirrer, nitrogen inlet-outlet lines, a thermometer, and a Dean-Stark trap, were placed with poly(oxyethylene-oxypropylene) bis(2aminopropyl ether) at $\sim 2000 M_{\mathrm{w}}$, i.e., Jeffamine ${ }^{\circledR} \mathrm{ED}-$ $2001,(20.0 \mathrm{~g}, 10 \mathrm{mmol})$ and toluene $(100 \mathrm{~mL})$. The mixture was heated to distill off a portion of toluene at 100 $-110^{\circ} \mathrm{C}$. After cooling to room temperature, isophorone diisocyanate $(1.11 \mathrm{~g}, 5 \mathrm{mmol})$ was added to the mixture in one portion by using a syringe. The mixture was stirred and maintained for $2-3 \mathrm{~h}$ at room temperature and then raised slowly to $110^{\circ} \mathrm{C}$ and hold at this temperature. The reaction was monitored by infra-red analysis to show the disappearance of the isocyanate absorption at $2270 \mathrm{~cm}^{-1}$. The mixture was further heated to $125^{\circ} \mathrm{C}$ to remove most of toluene solvent, then poured into a flat aluminum-foil mold and kept in a vacuum oven at $110^{\circ} \mathrm{C}$ for overnight. The solid sample plaque was then conditioned at room temperature for at last 1 week under atmosphere of $50 \%$ relative humidity. The surface resistivity was measured to have a reading of $10^{8.0} \Omega \mathrm{sq}^{-1}$. The absorption of $1107 \mathrm{~cm}^{-1}$ (vs., $\mathrm{C}-\mathrm{O}-\mathrm{C}$ ), $1638 \mathrm{~cm}^{-1}$ and $1555 \mathrm{~cm}^{-1}\left(\mathrm{~m}, \mathrm{NHCO}^{-\mathrm{NH}}\right)$, and $3200-$ $3400 \mathrm{~cm}^{-1}(\mathrm{~m}, \mathrm{~N}-\mathrm{H})$ were observed.

\section{ED-2001/IPDI Adduct at 1:1 Stoichiometric Ratio}

By adapting the similar procedures as described above, the mixture of Jeffamine ${ }^{\circledR}$ ED-2001 (17.8 g, 8.92 $\mathrm{mmol})$, toluene $(100 \mathrm{~mL})$ and isophorone diisocyanate $(1.98 \mathrm{~g}, 8.92 \mathrm{mmol})$ allowed to react. After the completion of reaction, the resultant liquid was poured into an aluminum mold and kept in an oven at $110^{\circ} \mathrm{C}$ for overnight. At room temperature, the solid sample plaque was measured to have a reading of surface resistivity at $10^{8.3} \Omega \mathrm{sq}^{-1}$. Infra-red spectrum of this sample showed $3305 \mathrm{~cm}^{-1}$ (m, N-H), $1642 \mathrm{~cm}^{-1}, 1560 \mathrm{~cm}^{-1}$ (m, NHCO$\mathrm{NH})$, and $1104 \mathrm{~cm}^{-1}$ (s, C-O-C). Other poly(oxyalkylene)-segmented urea oligomers and polyureas were prepared by using the similar procedures. Preparation of polyurethane was carried out as described elsewhere. ${ }^{13}$

\section{Characterizations}

Surface resistivity was measured by using a ST-3 Model (Simco Co.) tester according to the ASTM method D 257-93. The measurement is in the unit of ohm/square or $\Omega \mathrm{sq}^{-1}$ in which the size of square is immaterial. FTIR analyses were examined by using a Perkin-Elmer Paragon 500 FT-IR Spectrometer with a resolution of 4 $\mathrm{cm}^{-1}$. The average molecular weight was estimated by using Gel Permeation Chromatography (Waters GPC, 515 HPLC pump, 717 autosampler, 2410 refractive index detector) and using THF as eluent (flow rate: $1.0 \mathrm{~mL}$ $\min ^{-1}$ ), with the calibration by the standard polystyrenes. The thermal analyses were performed on a Seiko SII model SCC/5200 Differential Scanning Calorimeter from Seiko Instruments and Electronics Ltd. Sample size of 5 to $8 \mathrm{mg}$ on a sealed aluminum pan was generally used. The analyses were carried out in the temperature ranging from $-100^{\circ} \mathrm{C}$ to $180^{\circ} \mathrm{C}$ at a heating rate of $10^{\circ} \mathrm{C}$ per minute in nitrogen flow of $30 \mathrm{~mL} \mathrm{~min}{ }^{-1}$. The enthalpy of melting $(\Delta H)$ was determined by integration of the peak area under linear baseline, and peak values of the thermogram was reported as melting point $\left(T_{\mathrm{m}}\right)$. Water adsorption (WS) of the polyureas was measured by TGA. Sample size of 5 to $6 \mathrm{mg}$ on a aluminum pan was used. The ability of water adsorption is expressed by the difference of the weight gains,

$$
\mathrm{WS}=\left[\left(W_{\mathrm{s}}-W_{\mathrm{d}}\right) / W_{\mathrm{d}}\right] \times 100 \%
$$

where $W_{\mathrm{s}}$ and $W_{\mathrm{d}}$ were the weight of water-absorbed samples which were maintained in the atmosphere of $50 \%$ relative humidity under room temperature and dry samples which were dried at $110^{\circ} \mathrm{C}$ in vacuum oven, respectively.

\section{RESULTS AND DISCUSSION}

\section{Surface Resistivity of the Poly(oxyalkylene)amine Start-} ing Materials

Among starting amines, the poly(oxypropylene) (POP) 
diamines-derived compounds are amorphous liquids at ambient temperature and in hydrophobic nature. The poly(oxyethylene) (POE)-rich diamines with molecular weight higher than 2000, are semi-crystalline solids having surface resistivities from $10^{9.8}$ to $10^{10} \Omega \mathrm{sq}^{-1}$. The melting point and the heat of melting appear to be higher for the longer chains of POE diamines. With increasing the $M_{\mathrm{w}}$ from 2000 to 6000 , the $T_{\mathrm{m}}\left(37.6^{\circ} \mathrm{C}\right)$ and $\Delta H\left(122 \mathrm{~J} \mathrm{~g}^{-1}\right)$ for ED-2001 is compared to $T_{\mathrm{m}}\left(54.4^{\circ} \mathrm{C}\right)$ and $\Delta H\left(144 \mathrm{~J} \mathrm{~g}^{-1}\right)$ for ED-6000. For the purpose of comparison, PEG-1000, 2000, and 8000 were measured. Particularly, the higher molecular weight of PEG-8000 exhibited high $T_{\mathrm{m}}\left(61.8^{\circ} \mathrm{C}\right)$ and $\Delta H\left(189 \mathrm{~J} \mathrm{~g}^{-1}\right)$. Although they are soluble in water, the crystalline PEGs and POE-amines exhibit relatively low affinity for moisture and high surface resistivity. The high crystallinity seems to reduce the flexibility of polymer matrix and subsequently the mobility of electrostatic transferring.

Syntheses and Characterization of Poly(oxyalkylene)segmented Urea Oligomers and Polyureas

Adopting the poly(oxyalkylene)diamines as the starting materials (ED-2001, ED-6000, D-2000, and D-400), the polyureas were prepared by the reaction with IPDI or TDI according to the representative Scheme 1. FT-IR has been proved to be a suitable technique for characterization of urethane and urea. ${ }^{18-23}$ In the IR analysis of ureas, four spectral areas could be characteristically observed. They are (1) the $\mathrm{N}-\mathrm{H}$ stretching region between $3500-3200 \mathrm{~cm}^{-1}$, (2) the amide I region (also known as the carbonyl region) between 1800-1600 $\mathrm{cm}^{-1}$, (3) the isocyanate absorbance at $2270 \mathrm{~cm}^{-1}$ and (4) the amide II region below $1600 \mathrm{~cm}^{-1}$. The disappearance of the absorbance peak at around $2270 \mathrm{~cm}^{-1}$ and the appearance of the $v(\mathrm{C}=\mathrm{O})$ band of urea group are characteristic for the reaction progress. In viewing the literature, ${ }^{19-21}$ the assignment of the urethane/urea carbonyl and amine bands is fairly consistent for different structures, despite the localized vibrations in $\mathrm{N}-\mathrm{H}$ or $\mathrm{C}=\mathrm{O}$ stretching are very sensitive to the perturbation of hydrogen bonding. Both frequency shift and intensity changes characterize the specificity or magnitude of hydrogen bonding. The $v(\mathrm{C}=\mathrm{O})$ of urea group is distributed in the $1620-1669 \mathrm{~cm}^{-1}$ and $1675-1691 \mathrm{~cm}^{-1}$ representing the hydrogen bonded and free urea carbonyls, respectively. ${ }^{21}$ In the spectra of all synthesized urea oligomers and polyureas, the bands of $1633-1645 \mathrm{~cm}^{-1}$ were observed, indicating that the urea carbonyl were hydrogen bonded. The main $v(\mathrm{~N}-\mathrm{H})$ band was located at $3250-3350 \mathrm{~cm}^{-1}$ also indicating that many $-\mathrm{NH}$ groups were hydrogen bonded.

Average molecular weight of urea oligomers and polyureas are listed in Table I. It is found that all the diamine/IPDI urea oligomers exhibit multiple GPC peaks involving the distribution of the high molecular weight, the target molecular weight and the starting materials.
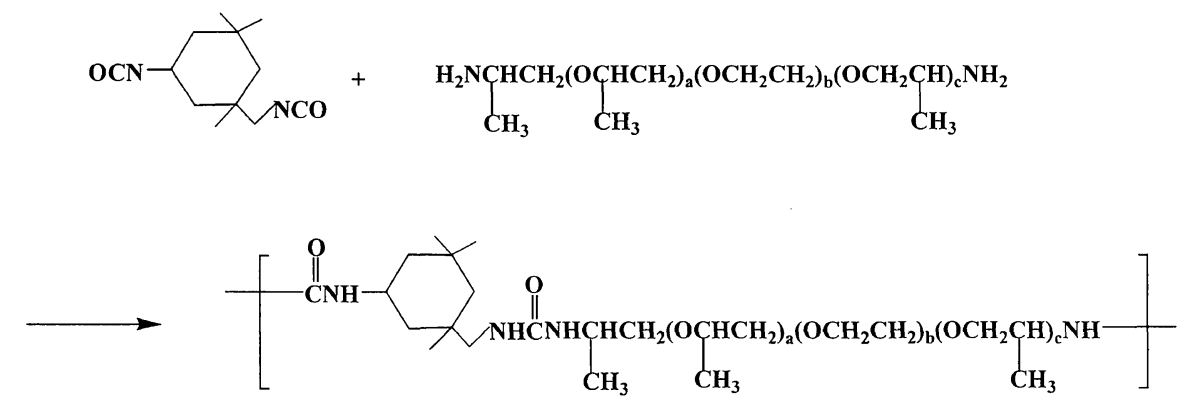

Scheme 1. Representative reaction of isophorone diisocyanate and poly(oxyethylene-oxypropylene)diamines.

Table I. GPC data of starting materials, ureas, and urethanes

\begin{tabular}{|c|c|c|c|c|}
\hline Composition $^{\mathrm{a}}$ & Molar ratio & $\begin{array}{c}\text { Concentration/ } \\
\text { wt }^{\mathrm{b}}{ }^{\mathrm{s}}\end{array}$ & $M_{\mathrm{n}} / \mathrm{g} \mathrm{mol}^{-1, \mathrm{~b}}$ & Polydispersity \\
\hline PPG-400 & - & 100 & 330 & 1.3 \\
\hline D-400 & - & 100 & 320 & 1.7 \\
\hline D-2000 & - & 95 & 1860 & 1.2 \\
\hline ED-2001 & - & 90 & 1520 & 1.9 \\
\hline ED-6000 & - & 90 & 6360 & 1.4 \\
\hline ED-2001/IPDI & $2: 1$ & $47,21,22$ & $10400,4500,1600$ & $1.2,1.0,1.1$ \\
\hline ED-2001/TDI & $2: 1$ & $34,18,27$ & $13800,7000,2200$ & $1.1,1.0,1.1$ \\
\hline D-2000/IPDI & $2: 1$ & $44,20,24$ & $10200,4600,1800$ & $1.1,1.0,1.1$ \\
\hline ED-6000/TDI & $2: 1$ & $28,20,40$ & $42300,21200,9300$ & $1.1,1.1,1.1$ \\
\hline ED-2001/IPDI & $1: 1$ & 85,6 & 40000,2700 & $1.5,1.1$ \\
\hline D-2000/IPDI & $1: 1$ & 85,6 & 41000,2800 & $1.5,1.1$ \\
\hline D-2000/TDI & $1: 1$ & 75,25 & 42000,2100 & $2.2,1.3$ \\
\hline ED-6000/IPDI & $1: 1$ & 60,34 & 30000,8200 & $1.2,1.2$ \\
\hline ED-6000/TDI & $1: 1$ & 68,28 & 31000,8200 & $1.4,1.2$ \\
\hline D-400/IPDI & $1: 1$ & 85,13 & 10300,400 & $1.7,1.3$ \\
\hline PPG-400/IPDI & $1: 1$ & 79,11 & 29000,430 & $1.9,1.2$ \\
\hline PPG-400/TDI & $1: 1$ & 78,13 & 25000,600 & $2.1,1.3$ \\
\hline
\end{tabular}

${ }^{a}$ ED-2001 and ED-6000: poly(ethylene glycol)bis(2-aminopropyl ether) at average $M_{\mathrm{w}}$ of 2000 and 6000 respectively. PPG-400: poly(propylene glycol) at average $M_{\mathrm{w}}$ of 400 . D-400 and D-2000: poly(propylene glycol)bis(2-aminopropyl ether) at average $M_{\mathrm{w}}$ of 400 and 2000 respectively. ${ }^{b}$ Based on number-average molecular weight as determined by GPC. 
There are two reasons for such a distribution: (1) the extremely fast reaction for amine and isocyanate and (2) the starting amine itself a distribution with high molecular weight analogs, which affect the amine/isocyanate molar ratio. The similar result was observed for the diamine/TDI urea oligomers, however the faster reactivity for TDI than IPDI affording even the higher molecular weight of diamine/TDI adducts than the diamine/ IPDI urea oligomers. It is believed that the synthesized urea oligomers and polyureas are linear products without the further reaction involving secondary active hydrogen in urea linkage which generally needs higher temperature $\left(>150^{\circ} \mathrm{C}\right)$.

\section{Surface Resistivity of POE Diamine-Derived Polyureas}

The poly(oxyalkylene)diamines can be classified into hydrophilic POE-rich and hydrophobic POP diamines. When these amines are allowed to react with diisocyanate at $2: 1$ and $1: 1$ molar ratios, the POE- or POPsegmented polyureas with various degree of hydrophilicity are obtained. These POE-derived polyureas are soluble in water, while the POP polyureas generally insol- uble in water. Some solubility data of these adducts in toluene, $\mathrm{THF}, \mathrm{CHCl}_{3}$, and $\mathrm{H}_{2} \mathrm{O}$ are summarized in Table II. Their surface resistivities were measured (Table III). It was observed that the POE-segmented polyureas had a generally lower surface resistivity than the corresponding POE-amine starting materials. For example, the ED-2001/TDI adducts at $2: 1$ and $1: 1$ molar ratios had a surface resistivity of $10^{7.4}$ and $10^{8.5} \Omega \mathrm{sq}^{-1}$ respectively in comparison with $10^{10.0} \Omega \mathrm{sq}^{-1}$ for ED-2001. Similar results were observed for the ED-6000 derived polyureas. This trend is also similar to the PEG derived polyurethane system as reported previously. ${ }^{13}$ The results involving PEG-2000 and 8000 derived polyurethanes are included in Table III for comparison. According to the DSC analyses, the diisocyanate coupled POEdiamines had lower melting points $\left(T_{\mathrm{m}}\right)$ and also lower melting heat $(\Delta H)$ than those of the crystalline starting amines. For example, in the series of ED-2001/TDI (1:1) adducts, the melting points dropped from $37.6^{\circ} \mathrm{C}$ to $29.7^{\circ} \mathrm{C}$ and the heat of melting lowered correspondingly from $122 \mathrm{~J} \mathrm{~g}^{-1}$ to $66 \mathrm{~J} \mathrm{~g}^{-1}$. Accordingly, the surface resistivity was observed to be $10^{8.5} \Omega \mathrm{sq}^{-1}$ for ED-2001/

Table II. Solubility of poly(oxyalkylene)-segmented polyureas and polyurethanes

\begin{tabular}{lcccc}
\hline Polyureas or $^{\mathrm{b}}$ & \multicolumn{5}{c}{ Solvent $^{\mathrm{a}}$} \\
\cline { 2 - 5 } Polyurethanes $^{\mathrm{n}}$ & Toluene & THF & $\mathrm{H}_{2} \mathrm{O}$ & $\mathrm{CHCl}_{3}$ \\
\hline ED-2001/IPDI & - & ++ & ++ & ++ \\
D-2000/TDI & + & ++ & - & ++ \\
ED-6000/IPDI & ++ & ++ & ++ & ++ \\
ED-6000/TDI & ++ & ++ & - & ++ \\
D-400/IPDI & - & - & - & - \\
D-400/TDI & ++ & ++ & - & ++ \\
PPG-400/IPDI & + & ++ & ++ & ++ \\
PPG-400/TDI & & + & + & + \\
\hline
\end{tabular}

${ }^{a}$ Solubility: $(0.5 \mathrm{~g} / 100 \mathrm{~g})$ at room temperature; ++ completely soluble; + partly soluble; - insoluble. ${ }^{\mathrm{b}}$ Prepared by using $1: 1$ molar ratio of $-\mathrm{NH}_{2}$ (or $\left.-\mathrm{OH}\right)$ to $-\mathrm{NCO}$.

Table III. Surface resistivity of poly(oxyalkylene)-segmented polyureas and polyurethanes

\begin{tabular}{|c|c|c|c|c|}
\hline $\begin{array}{l}\text { Composition }^{\mathrm{a}} \\
\text { (Molar ratio) }^{2}\end{array}$ & $T_{\mathrm{m}} /{ }^{\circ} \mathrm{C}$ & $\Delta H / \mathrm{J} \mathrm{g}^{-1}$ & $\begin{array}{c}\text { Surface resistivity/ } \\
10^{\mathrm{x}} \Omega \mathrm{sq}^{-1}\end{array}$ & Remarks \\
\hline \multicolumn{5}{|l|}{ ED-2001/TDI } \\
\hline $1: 0$ & 37.6 & 122 & 10.0 & Crystalline solid \\
\hline $2: 1$ & 36.6 & 96 & 7.4 & Orange, hygroscopic solid \\
\hline $1: 1$ & 29.7 & 66 & 8.5 & Yellowish, elastic, sticky solid \\
\hline \multicolumn{5}{|l|}{ ED-2001/IPDI } \\
\hline $1: 0$ & 37.6 & 122 & 10.0 & Crystalline solid \\
\hline $2: 1$ & 36.0 & 80 & 8.0 & Yellowish, opaque, sticky solid \\
\hline $1: 1$ & 27.8 & 64 & 8.3 & Semi-transparent solid \\
\hline \multicolumn{5}{|l|}{ PEG-2000/IPDI ${ }^{\mathrm{b}}$} \\
\hline $1: 0$ & 53.6 & 175 & 9.9 & Crystalline solid \\
\hline $2: 1$ & 52.3 & 137 & 9.6 & Yellowish, opaque, hard solid \\
\hline $1: 1$ & 38.6 & 77 & 8.8 & Yellowish, opaque, hard solid \\
\hline \multicolumn{5}{|l|}{ ED-6000/TDI } \\
\hline $1: 0$ & 54.4 & 144 & 9.8 & Crystalline solid \\
\hline $2: 1$ & 56.7 & 130 & 8.8 & Orange, opaque, hard solid \\
\hline $1: 1$ & 54.7 & 129 & 9.3 & Orange, opaque, hard solid \\
\hline \multicolumn{5}{|l|}{ ED-6000/IPDI } \\
\hline $1: 0$ & 54.4 & 144 & 9.8 & Crystalline solid \\
\hline $2: 1$ & 50.3 & 118 & 8.5 & Orange, opaque, hard solid \\
\hline $1: 1$ & 51.0 & 103 & 9.1 & Orange, opaque, hard solid \\
\hline \multicolumn{5}{|l|}{ PEG-8000/IPDI ${ }^{\mathrm{b}}$} \\
\hline $1: 0$ & 61.8 & 189 & 10.9 & Crystalline solid \\
\hline $2: 1$ & 60.5 & 152 & 8.7 & White, opaque, hard solid \\
\hline $1: 1$ & 59.8 & 141 & 8.7 & White, opaque, hard solid \\
\hline
\end{tabular}

${ }^{\mathrm{a}}$ ED-2001 and ED-6000: poly(ethylene glycol)bis(2-aminopropyl ether) at average $M_{\mathrm{w}}$ of 2000 and 6000 , respectively. PEG-2000 and PEG8000: poly(ethylene glycol) at average $M_{\mathrm{w}}$ of 2000 and 8000 , respectively. ${ }^{\mathrm{b}}$ Reported previously in reference 13. 
Table IV. Moisture absorption of ureas and urethane under 50\% relatively humidity at room temperature

\begin{tabular}{lccc}
\hline Composition $^{\text {a }}$ & Molar ratio & $\begin{array}{c}\text { Water } \\
\text { absorption/\% }\end{array}$ & Duration/day $^{\mathrm{b}}$ \\
\hline ED-2001/IPDI & $2: 1$ & 18 & 3 \\
ED-2001/IPDI & $1: 1$ & 15 & 3 \\
D-2000/IPDI & $1: 1$ & 3.2 & 4 \\
D-400/IPDI & $1: 1$ & 4.4 & 4 \\
PPG-400/IPDI & $1: 1$ & 3.2 & 4 \\
\hline
\end{tabular}

${ }^{a}$ ED-2001: poly(ethylene glycol)bis(2-aminopropyl ether) at average $M_{\mathrm{w}}$ of 2000. D-2000: poly(propylene glycol)bis(2-aminopropyl ether) at average $M_{\mathrm{w}}$ of 2000. PPG-400: poly(propylene glycol) at average $M_{\mathrm{w}}$ of 400 . D-400: poly(propylene glycol)bis-(2aminopropyl ether) at average $M_{\mathrm{w}}$ of 400 . ${ }^{\mathrm{b}}$ At equilibrium.

TDI adduct at $1: 1$ molar ratio and $10^{10.0} \Omega \mathrm{sq}^{-1}$ for ED2001. Similar trend was observed in the cases of ED$6000 /$ IPDI or TDI. It appears that the surface resistivity is inversely proportioned to the molecular alignment or the degree of crystallinity. Generally, the oligomeric and polymeric ureas have higher segmental mobility of POE blocks and consequently the electrostatic transferring than that of the POE-amine starting materials.

However, in this study, not all of samples obey the rule of crystallinity. Some polyureas had higher degree of crystallinity but lower surface resistivity. In the cases of ED-2001/TDI and ED-2001/IPDI, their melting points and melting enthalpy are generally higher for $2: 1$ adduct than the corresponding $1: 1$ adduct. And in each case, the $2: 1$ adducts had a lower surface resistivity. These trends are consistent throughout various molar ratios of ED-2001 and ED-6000/TDI adducts. Accordingly, the followings are observed: $10^{7.4}$ (at $2: 1$ ) vs. $10^{8.5}$ (at $1: 1$ ) for ED-2001/TDI; $10^{8.0}$ (at $2: 1$ ) vs. $10^{8.3}$ (at $1: 1$ ) for ED-2001/IPDI; $10^{8.8}$ (at $2: 1$ ) vs. $10^{9.3}$ (at $1: 1$ ) for ED6000/TDI and $10^{8.5}$ (at $2: 1$ ) vs. $10^{9.1}$ (at $1: 1$ ) for ED$6000 /$ IPDI. It seems there is another factor to overweight the effect of the degree of crystallinity for the electron transferring. At 2:1 molar ratio of diamine/diisocyanate, the adducts consist of amine terminating functionalities which can enhance the high affinity for moisture absorbing through hydrogen bonding. In appearance, these adducts were tacky and hygroscopic. Presumably, the partial ionization of water molecules can be readily associated with amine termini to form quaternary salts which in turn contribute to the increase of conductivity.

The ED-2001/IPDI derived oligomeric urea and polyurea were subjected to a vacuum oven at $110^{\circ} \mathrm{C}$ to remove water and then maintained in an atmosphere of $50 \%$ relative humidity under room temperature. The differences in weights were measured to estimate the water absorption (Table IV). In general, the moisture weight gains reached equilibrium after 3 days. It was found that the oligomeric urea tends to adsorb more water than polyurea. The result is correspondent to the observed surface resistivities.

\section{Relative Hydrophilicity of POE vs. POP}

It is well known that POE can generally associate with moisture at a ratio of each ether oxygen to two water molecules. ${ }^{11}$ The POP, on the contrary, has a hydrophobic property at molecular weights over 800 . How-
Table V. Surface resistivity of polyureas and polyurethanes

\begin{tabular}{ccl}
\hline $\begin{array}{c}\text { Composition } \\
\text { (Molar ratio) }\end{array}$ & $\begin{array}{c}\text { Surface resistivity/ } \\
10^{\times} \Omega \mathrm{sq}^{-1}\end{array}$ & \multicolumn{1}{c}{ Remarks } \\
\hline D-2000/IPDI & & Liquid \\
$1: 1$ & - & \\
D-2000/TDI & & Sticky, soft solid \\
$1: 1$ & 9.0 & Elastic, sticky solid \\
ED-2001/TDI & & \\
$1: 1$ & 8.5 & Transparent solid \\
ED-2001/IPDI & & \\
$1: 1$ & 8.3 & Opaque, hard solid \\
PEG-2000/IPDI & & \\
$1: 1$ & 8.8 & $\begin{array}{l}\text { Liquid } \\
\text { PPG-400/IPDI }\end{array}$ \\
$2: 1$ & - & Transparent, elastic solid \\
$1: 1$ & 10.3 & \\
D-400/IPDI & & Liquid \\
$2: 1$ & - & Transparent, elastic solid \\
$1: 1$ & 9.8 & \\
PPG-400/TDI & & Liquid \\
$2: 1$ & - & Transparent solid \\
$1: 1$ & 11.2 & Liquid \\
D-400/TDI & - & Transparent solid \\
$2: 1$ & 10.7 & \\
$1: 1$ &
\end{tabular}

${ }^{\text {a }}$ ED-2001: poly(ethylene glycol)bis(2-aminopropyl ether) at average $M_{\mathrm{w}}$ of 2000. D-2000: poly(propylene glycol)bis(2-aminopropyl ether) at average $M_{\mathrm{w}}$ of 2000. PPG-400: poly(propylene glycol) at average $M_{\mathrm{w}}$ of 400 . D-400: poly(propylene glycol)bis-(2aminopropyl ether) at average $M_{\mathrm{w}}$ of 400 .

ever, all POPs are amorphous while high molecular weight POEs are semi-crystalline. The relative degree of hydrophilicity between POEs and POPs can be expressed by their hygroscopicity and surface resistivities. In Table V, the amorphous and liquid POP was coupled through TDI into a transparent, yellowish and sticky material having surface resistivity of $10^{9.0} \Omega \mathrm{sq}^{-1}$ for D2000/TDI. In comparison, ED-2001/TDI at $10^{8.5} \Omega \mathrm{sq}^{-1}$ was obtained. The hydrophilicity can be correlated to the water adsorption directly. For comparing the ED-2000/ IPDI and D-2000/IPDI polyureas, the POE-derived polyurea had almost five times water adsorption than that of POP-derived polyurea. The hydrophilicity or the affinity for absorbing moisture in achieving low surface resistivity is therefore demonstrated. The differences in chemical structure are illustrated in Figure 2.

\section{Relative Hydrophilicity of Urea vs. Urethane}

There are significant structural differences between the PEG or PPG derived polyurethanes and POE or POP derived polyureas. As discussed above, the amineterminating structures of ureas have demonstrated lower surface resistivity. However, in the urethane system, at $2: 1$ molar ratio of $-\mathrm{OH} /-\mathrm{NCO}$, the resulting hydroxyl termini had no effect on the conductivity. In fact, PEG-2000/IPDI at 2:1 gave a higher resistivity than that at $1: 1$, which is expected if the segmental mobility is taken into account.

Another structural difference is the linkage functionality. As shown in Figure 2, the possible formation of water associated hydrogen bonding with urea (NHCONH) is more than with urethane (NHCOO). The moisture association is therefore higher in urea structures. The trend showing a different surface conductivity was not obvious between ED-2001/IPDI and PEG-2000/ 


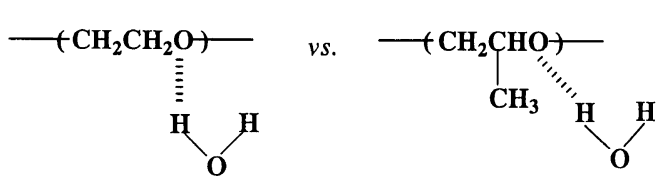

( higher affinity)

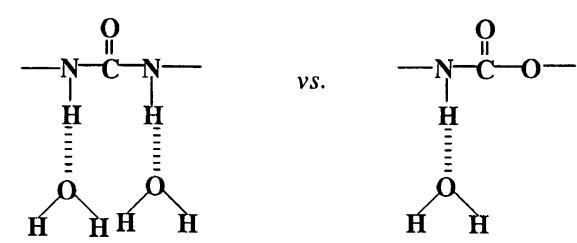

( more possible H-bonds )

Figure 2. Hydrophilicity of poly(oxyethylene) vs. poly(oxypropylene) and urea vs. urethane linkages.

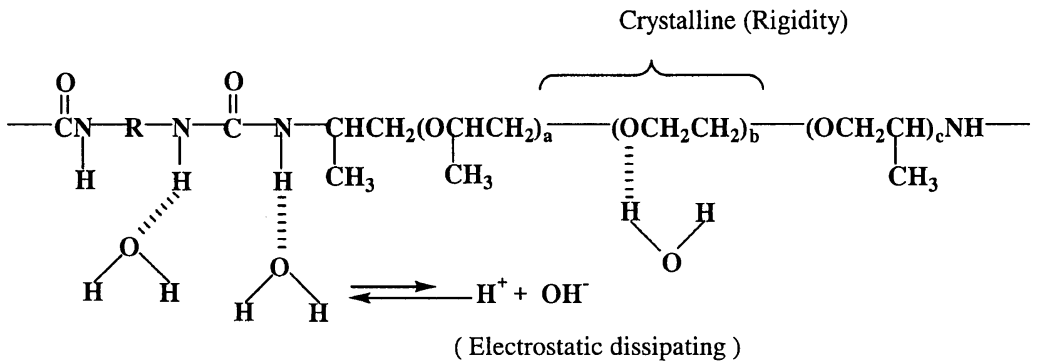

Figure 3. Hydrogen bonding and mobility of poly(oxyethylene)-segmented polyureas.

IPDI (in Table III) because of low density of linkage groups and high crystallinity of POE segments. The difference in urea/urethane linkages is better compared by the low molecular weight of POP-diamine (i.e., D-400) and its precursor poly(propylene glycol) (i.e., PPG-400), as shown in Table V. The amorphous, liquid D-400 and PPG-400 were coupled with both IPDI and TDI. At 2:1 molar ratio, these adducts were in liquid forms. However, transparent and elastic solid plaques were obtained with the following surface resistivity: $10^{10.3}$ $\Omega \mathrm{sq}^{-1}$ for PPG-400/IPDI vs. $10^{9.8} \Omega \mathrm{sq}^{-1}$ for D-400/IPDI, and $10^{11.2} \Omega \mathrm{sq}^{-1}$ for PPG-400/TDI vs. $10^{10.7} \Omega \mathrm{sq}^{-1}$ for D-400/TDI. In all cases, the urea linkages are more hydrophilic than the urethanes. The water adsorption cited in Table IV also shows the same trend. The relationship between the linkage functionality and the surface resistivity is therefore demonstrated.

\section{Mechanism and Trend of Electrostatic Dissipating Ability}

It is generally believed that the electrostatic dissipating ability is attributed to the hydrophilic segments in amphiphilic polymers. In the previous studies, ${ }^{13-15}$ we have shown the weight composition of the POE segments in polymer is directly correlated with the property of surface resistivity. The overall view of electrostatic dissipation through the partial ionization of water molecules associated by hydrogen bonding is conceptually presented in Figure 3. Other supplementary factors such as the segmental rigidity due to crystallinity and the amine termini are qualitatively contributed to the mechanism.

\section{CONCLUSIONS}

The coupling of various POE-rich diamines and diisocyanates generated a series of poly(oxyethylene)segmented urea oligomers and polymers with considerably low surface resistivity ranging from $10^{9.3}$ to $10^{7.4}$ $\Omega \mathrm{sq}^{-1}$. Their surface resistivities are affected by the segmental crystallinity, the terminal and the linkage functionalities, as well as the different hydrophilicity between POE and POP. The urea is more hydrophilic than the urethane linkages. The amine termini are highly effective and the POE is more effective than the POP for lowering surface resistivity. The mechanism of electrostatic dissipating involving water molecule association with the hydrophilic segments in the polymer backbone through hydrogen bonding is suggested.

Acknowledgment. The authors are grateful to the National Science Council of Taiwan (ROC) for the financial support of this work (Grant NSC-86-2113-M-005002).

\section{REFERENCES}

1. R. Gachter and H. Muller, in "Plastics Additives Handbook", Hanser Publishers, Munich, 1984

2. B. Lee, Electrostatic dissipating compositions, U. S. Patent 5 237009 (Aug. 17, 1993).

3. L. V. Interrante, L. A. Casper, and A. B. Ellis, in "Materials Chemistry, An Emerging Discipline", Advances in Chemistry Series 245, The American Chemical Society, Publishers LTD, Washington, D.C., 1995, p 107.

4. R. G. Linford, Ed., "Electrochemical Science and Technology of Polymers 1", Elsevier Applied Science, London, 1987, p 67.

5. B. Scrosati, Ed., "Application of Electroactive Polymers", Chapman and Hall, London, 1993, p 75.

6. H. G. Kiess, in "Conjugated Conducting Polymers", SpringerVerlag, Berlin, 1992, p 7.

7. J. R. MacCallum and C. A. Vincent, Ed., "Polymer Electrolyte Reviews 1 and 2", Elsevier Applied Science, London, 1987, p 173 and 1989, p 191.

8. T. Fukumoto, K. Yano, and M. Iwamoto, Polymer-ester amide and permanently antistatic resin composition, U. S. Patent 5 096995 (Mar. 17, 1992).

9. K. Okazaki, A. Nakagawa, and K. Sugii, Composite filaments and fibers, U. S. Patent 3558419 (Jan. 26, 1971).

10. I. Piirma, in Surfactant Science Series, 34, "Polymeric Surfactant”, Marcel Dekker, Inc., New York, N.Y., 1992, p 17.

11. J. M. Harris, Ed., "Poly(Ethylene Glycol) Chemistry: Biotechnical and Biomedical Applications", Plenum Publishing Cor- 
poration, New York, N.Y., 1992, p 5.

12. S. L. Cooper and A. V. Tobolsky, J. Appl. Polym. Sci., 10, 1937 (1966).

13. J. J. Lin and Y. C. Chen, Polym. Int., 48, 57 (1999).

14. M. Y. Yang and J. J. Lin, Ind. Eng. Chem. Res., 37, 4284 (1998).

15. J. J. Lin, F. P. Tseng, and F. C. Chang, Polym. Int., 49, 387 (2000).

16. P. H. Moss, Nickel-Copper-Chromia catalyst and the preparation thereof, U. S. Patent 3152998 (Oct. 13, 1964).

17. E. L. Yeakey, Process for preparing polyoxyalkylene polyamines, U. S. Patent 3654370 (Apr. 4, 1972).

18. C. P. Christenson, M. A. Harthcock, M. D. Meadows, H. L Spell, W. L. Howard, M. W. Creswick, R. E. Guerra, and R. B. Turner, J. Polym. Sci., Part B: Polym. Phys., 24, 1401 (1986).

19. H. S. Lee and S. L. Hsu, Macromolecules, 22, 1100 (1989).

20. A. G. Strikovsky and V. V. Zharkov, Polymer, 34, 3397 (1993).

21. N. Luo, D. N. Wang, and S. K. Ying, Macromolecules, 30, 4405 (1997).

22. K. Hong and S. Park, Mater. Sci. Eng., A 272, 418 (1999).

23. C. T. Zhao and M. N. de Pinho, Polymer, 40, 6089 (2000). 